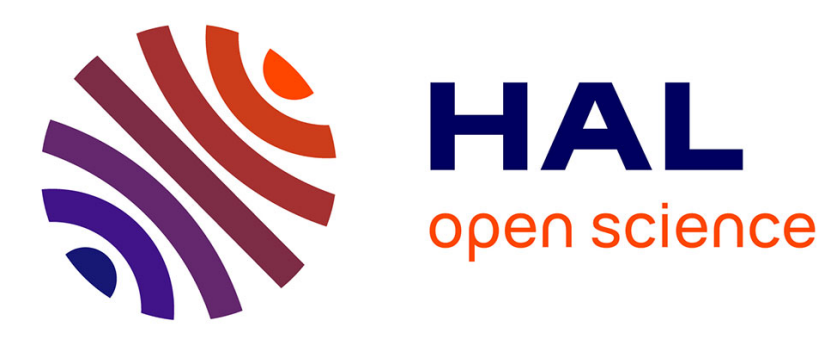

\title{
Design of an ultra compact electronically tunable microwave impedance transformer
}

A. Jrad, A.-L. Perrier, R. Bourtoutian, J.-M. Duchamp, Philippe Ferrari

\section{To cite this version:}

A. Jrad, A.-L. Perrier, R. Bourtoutian, J.-M. Duchamp, Philippe Ferrari. Design of an ultra compact electronically tunable microwave impedance transformer. Electronics Letters, 2005, 41 (12), pp.707709. 10.1049/el:20050689 . hal-01814633

\section{HAL Id: hal-01814633 \\ https://hal.univ-smb.fr/hal-01814633}

Submitted on 13 Jun 2018

HAL is a multi-disciplinary open access archive for the deposit and dissemination of scientific research documents, whether they are published or not. The documents may come from teaching and research institutions in France or abroad, or from public or private research centers.
L'archive ouverte pluridisciplinaire HAL, est destinée au dépôt et à la diffusion de documents scientifiques de niveau recherche, publiés ou non, émanant des établissements d'enseignement et de recherche français ou étrangers, des laboratoires publics ou privés. 


\section{Design of an ultra compact electronically tunable microwave impedance transformer}

A. Jrad, A.-L. Perrier, R. Bourtoutian, J.-M. Duchamp and P. Ferrari

A novel ultra compact microwave tuneable impedance transformer topology is proposed. It consists of a classical $\pi$ CLC network where an equivalent tuneable inductance is realised with a high impedance transmission line in series with fixed inductance and a diode's varactors. The realised hybrid prototype at $900 \mathrm{MHz}$ operating frequency is only $0.06 \lambda$-long. Impedance loads from 16.5 to $280 \Omega$ can be matched with a return loss better than $-20 \mathrm{~dB}$, and the relative bandwidth equals $\pm 36 \%$ for a fixed $50 \Omega$ load.

Introduction: Impedance transformers are widely used for microwave applications such as matching networks, filters, power dividers, etc. Tunable impedance transformers could offer interesting possibilities and constitute a great challenge in the field of modern telecommunication systems. For example, they could be used in microwave amplifiers matching networks to modify, after realisation, their behaviour, so that the optimal characteristics of the amplifier could be reached, even if its model is not perfectly known a priori. Also, they could be used to tune amplifier matching networks for wideband applications without sacrificing the amplifier characteristics, power gain or noise factor. We could also design tunable power dividers.

Some realisations have been published on microwave tuneable impedance transformers, but not many. Sinsky and Westgate have presented a topology based on a $\pi C L C$ (capacitor - inductor capacitor) network [1]. The three elements have to be tunable to achieve a tunable impedance transformer. Tunable capacitors are realised with reverse biased Schottky diodes acting as varactors. The tunable inductor, in series between the two shunt capacitors, is realised with a shunt varactor connected between two quarter wave transmission lines.

The use of quarter wave transmission lines is a problem. They reduce the device bandwidth, lead to a relatively long device (half wavelength), increasing losses, and induce a cost due to the used surface for MMIC devices. In [2], we have published an original topology, not based on a $\pi C L C$ network. Its length is about a third of a wavelength, and complex loads can be matched, with a wide coverage of the Smith chart.

In this Letter, we propose a topology based on a $\pi C L C$ network, like [1], but the tunable inductor is not realised with a varactor inserted between two quarter wavelength transformers, leading to very small devices with a length of a few percent of wavelength. The tunable inductor is achieved by inserting a varactor $\left(C^{\prime}\right)$ in series with an inductor $(L)$, leading to a resonant circuit. Working above the resonant frequency leads to the realisation of an equivalent tunable inductor. To minimise insertion losses, the inductor value $L$ is realised in practice with a short high impedance transmission line in series with a fixed inductance. Our first concepts, at frequencies from 1 to $10 \mathrm{GHz}$, have shown that this approach leads to impedance transformers of very small length, always lower than $10 \%$ of the guided wavelength. Moreover, the bandwidth is only limited by the varactors and the fixed inductance characteristics: capacitor tuning range, parasitic elements and quality factors.

Background theory: The electrical equivalent circuit of the tunable transformer realised is given in Fig. 1. Varactors $\left(C\right.$ and $\left.C^{\prime}\right)$ are realised with reverse biased Schottky diodes. The varactors' parasitic elements have not been represented in Fig. 1. However they have to be taken into account during the design procedure.

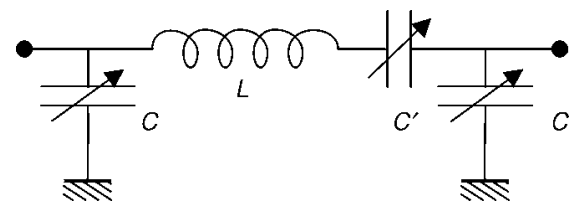

Fig. 1 Electrical equivalent circuit for the tunable transformer

The equivalent impedance $\bar{Z}$ of the $L C^{\prime}$ circuit can be written as

$$
\bar{Z}=\left[1-\left(\omega / \omega_{c}\right)^{2}\right] /\left(j C^{\prime} \omega\right)
$$

where $\omega_{c}=1 / \sqrt{ }\left(L C^{\prime}\right)$ is the circuit resonant frequency.
When the condition $\omega>\omega_{c}$ is realised, the impedance $\bar{Z}$ represents an equivalent inductor $L_{e q}$

$$
L_{e q}=\left[\left(\omega / \omega_{c}\right)^{2}-1\right] /\left(C^{\prime} \omega^{2}\right)
$$

This equivalent inductor is tunable because it is related to the varactor capacitance $C^{\prime}$ (and also $\omega_{c}$ ). So it can be said that an equivalent electronically tunable inductor has been realised.

The working equations are given in [1]. Here the inductor is replaced by the equivalent tunable inductor. If the impedance transformer is loaded by an impedance $Z_{l}$, the input impedance $Z_{\text {in }}$ can be written as

$$
Z_{\text {in }}=\left(\frac{L_{e q}}{C}\right) \frac{1}{Z_{l}^{\prime}}
$$

and the operating frequency $\omega_{f}$ is

$$
\omega_{f}=1 / \sqrt{L_{e q} C}
$$

With relations (3) and (4), the expressions for $C$ and $L_{e q}$ can be derived

$$
L_{e q}=\sqrt{Z_{l} Z_{\text {in }}} / \omega_{f} \text { and } C=1 /\left(\omega_{f} \sqrt{Z_{l} Z_{\text {in }}}\right)
$$

For the design, the bias point is chosen for $Z_{l}=50 \Omega$, so that loads around $50 \Omega$ can be matched.

Realisation and results: The design has been achieved with ANSOFT Designer [3]. A circuit optimisation, based on the minimisation of $\left|S_{11}\right|$, to obtain a good return loss, has been carried out for the calculus of the high impedance transmission line used to realise the series inductance $L$. To validate our approach, a tunable impedance transformer prototype has been realised in a hybrid technology, with an operating frequency around $900 \mathrm{MHz}$. MACOM varactor diodes MA46H071 have been used. These varactors exhibit a zerobiased capacitance $C_{j 0}=C_{\max }=2.45 \mathrm{pF}$, a capacitance tuning ratio $C_{\max } / C_{\min }=7$, a series resistance $R_{s}=0.4 \Omega$, a parasitic series inductance $L_{s}=1.3 \mathrm{nH}$ and a case capacitance $C_{c}=0.13 \mathrm{pF}$. The parasitic series inductance is an important parameter. It is added to the high impedance transmission line and the fixed inductance $L^{\prime}$ to realise the inductor $L$. The fixed inductance value is $22 \mathrm{nH}$, leading to a tunable inductance from 0 to $17 \mathrm{nH}$. A coplanar waveguide (CPW) technology has been used. So two pairs of diodes are necessary to realise the shunt capacitors $C$. The transformer was fabricated on Rodgers RO4003 substrate, with a relative permittivity $\varepsilon_{r}=3.36$, high $h=813 \mu \mathrm{m}$ and dielectric losses $\operatorname{tg} \delta=0.0015$. The high impedance transmission line characteristics are as follows: characteristic impedance $Z_{C}=102 \Omega$, length $d=\lambda_{g} / 16$, where $\lambda_{g}$ is the guided wavelength, CPW conductor width $W=3.27 \mathrm{~mm}$, and gap $S=2 \mathrm{~mm}$. The diode bias is different for $C$ and $C^{\prime}$, respectively $V_{1}$ and $V_{2}$ voltages. The voltage bias $V_{2}$ has been applied from the top of the CPW high impedance transmission line. Fig. 2 describes the topology of the realised impedance transformer. A gap of length $250 \mu \mathrm{m}$ is necessary for the isolation of the two bias voltages. Then a capacitance $C_{s}$ of $1 \mathrm{nF}$ is added to minimise insertion losses at the operating frequency.

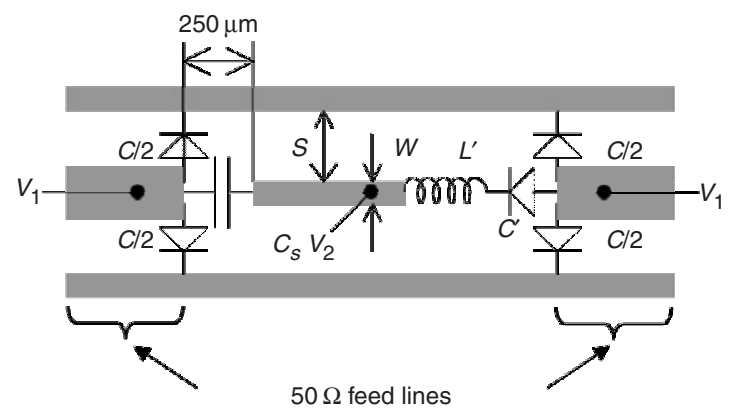

Fig. 2 Topology of the realised impedance transformer

Two types of measurement have been carried out with a vector network analyser (ANRITSU Wiltron 360) after a TRL calibration procedure. First, the tunable bandwidth has been measured for a $50 \Omega$ fixed load. Next the tunable load has been measured at a fixed frequency of $900 \mathrm{MHz}$. A series capacitor of $1 \mathrm{nH}$ is always connected in series with the load to avoid the presence of an important DC current 
through the load. This capacitor is a short circuit at the operating frequency.

Fig. 3 shows the measurement results for a $50 \Omega$ fixed load. Only the extreme measured frequencies are showed.

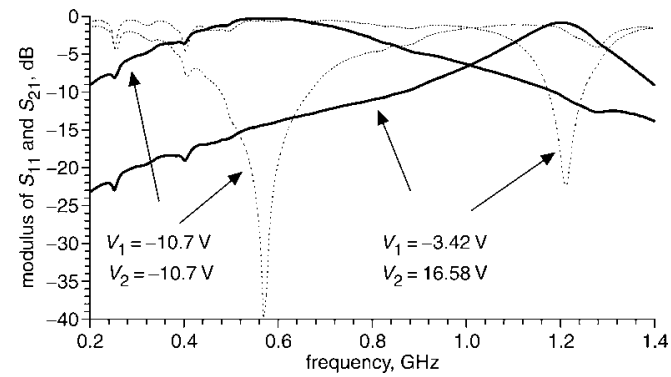

Fig. 3 Measurement results for $50 \Omega$ fixed load - . - modulus of $S_{11} \quad$ modulus of $S_{21}$

The load can be tuned with $\left|S_{11}\right|$ better than $-20 \mathrm{~dB}$, from $570 \mathrm{MHz}$ to $1.23 \mathrm{GHz}$, ie $\pm 36 \%$ around $900 \mathrm{MHz}$. Insertion losses are always lower than $1 \mathrm{~dB}$. These results are in good agreement with simulations (see Fig. 4). The shift in the operating frequencies can be due to a bad estimate of the diode's parasitics in the manufacturer model.

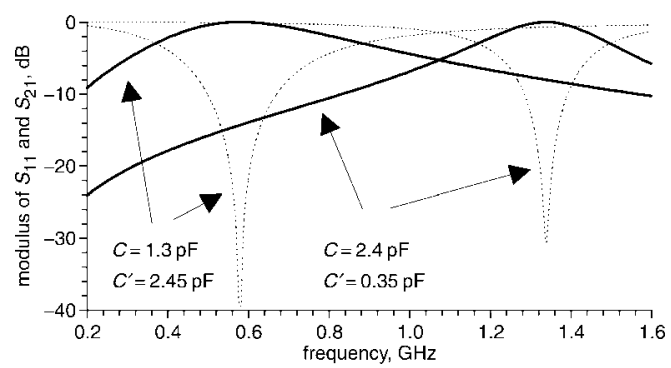

Fig. 4 Simulation results for $50 \Omega$ fixed load - - modulus of $S_{11}$ - modulus of $S_{21}$

Fig. 5 shows the measurement results for a $900 \mathrm{MHz}$ fixed frequency, and a variable load. The tuning is possible $\left(\left|S_{11}\right|<-20 \mathrm{~dB}\right)$ for load impedances from 16.5 to $280 \Omega$, i.e. from 33 to $560 \%$ of $50 \Omega$. The minimum and maximum load impedances that can be matched are only limited by diode parasitics. These values will depend therefore upon the diode characteristics.

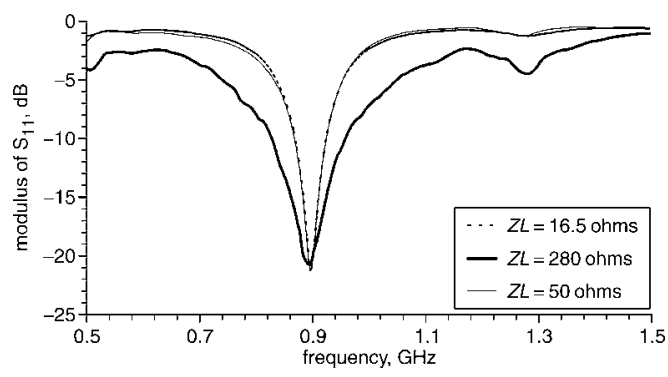

Fig. 5 Modulus of $S_{11}$ for extreme loads, $16.5 \Omega$ and $280 \Omega$, at $900 \mathrm{MHz}$

Conclusion: An ultra compact microwave tunable impedance transformer has been realised and measured, based on the principle of an equivalent tunable inductor. The prototype operating frequency is $900 \mathrm{MHz}$. Its length is about $6 \%$ of the guided wavelength. Results show good agreement between measurements and simulations. A fixed load can be matched over a wide bandwidth $( \pm 36 \%$ for a fixed $50 \Omega$ load) and for a large load impedance variation, from 16.5 to $280 \Omega$, at a fixed frequency $(900 \mathrm{MHz})$. These results are very interesting for microwave monolithic integrated circuit applications.

\section{(C) IEE 2005}

15 March 2005

Electronics Letters online no: 20050689

doi: 10.1049/el:20050689

A. Jrad (LPA, Université Libanaise, Faculté des Sciences section III, Tripoli, Liban)

A.-L. Perrier and J.-M. Duchamp (LAHC, Université de Savoie, 73376 Le Bourget-du-lac CEDEX, France)

R. Bourtoutian and P. Ferrari (IMEP, ENSERG, 23 av. des Martyrs BP 257, 38016 Grenoble Cedex 1, France)

E-mail: ferrari@enserg.fr

\section{References}

1 Sinsky, J.H., and Westgate, C.R.: 'Design of an electronically tunable microwave impedance transformer'. IEEE Int. Microw. Symp. Dig. MTT-S, June 1997, Vol. 2, pp. 647-650

2 Perrier, A.-L., Ferrari, P., Duchamp, J.-M., and Vincent, D.: 'A varactor tunable complex impedance transformer'. 34th Eur. Microw. Conf. EuMC'04, Amsterdam, 25-27 Oct. 2004

3 ANSOFT Designer, ANSOFT Corporate, 225 West Station Square Drive Suite 200, Pittsburgh, PA 15219, USA 